\title{
RESIDÊNCIA PEDAGÓGICA GEOGRAFIA/UNIMONTES: RELATO DE EXPERIÊNCIA EM TEMPO DE PANDEMIA DO COVID-19
}

\section{PEDAGOGICAL RESIDENCE GEOGRAPHY/UNIMONTES: REPORT OF EXPERIENCE IN TIME OF THE COVID-19 PANDEMIC}

\section{GEOGRAFÍA DE RESIDENCIA PEDAGÓGICA/UNIMONTES: INFORME DE LA EXPERIENCIA EN TIEMPOS DE LA PANDEMIA DE COVID-19}

\author{
Vanessa Tamiris Rodrigues Rocha ${ }^{1}$ https://orcid.org/0000-0001-8223-2785 \\ Maria Júlia de Souza Leite ${ }^{2}$ https://orcid.org/0000-0002-7582-3787 \\ Jéssica Lorrany Sant'Ana Rodrigues ${ }^{3}$ https://orcid.org/0000-0002-9531-5392 \\ Dulce Pereira dos Santos ${ }^{4}$ https://orcid.org/0000-0003-4809-2824 \\ Rahyan de Carvalho Alves ${ }^{5}$ https://orcid.org/0000-0001-7225-5959
}

\footnotetext{
${ }^{1}$ Acadêmica do curso de Licenciatura em Geografia - Universidade Estadual de Montes Claros. E-mail: vanessatamiiris@gmail.com

${ }^{2}$ Egressa do curso de Licenciatura em Geografia - Universidade Estadual de Montes Claros. E-mail: maju.geo18@gmail.com

${ }^{3}$ Egressa do curso de Licenciatura em Geografia - Universidade Estadual de Montes Claros. E-mail: jessicasantaro@gmail.com

${ }^{4}$ Doutora em Geografia - Professora da Universidade Estadual de Montes Claros E-mail: dulcepereira.pereira@gmail.com

${ }^{5}$ Doutor em Geografia - Professor da Universidade Estadual de Montes Claros. E-mail: rahyan.alves@unimontes.br
}

\section{RESUMO}

Diante das mudanças ocorridas na sociedade, sobretudo, no ano de 2020, no qual a humanidade foi surpreendida pela pandemia do Coronavírus, se torna fundamental o desenvolvimento de novas práticas educacionais para dar continuidade ao processo de ensino e aprendizagem. Isto posto, o objetivo deste artigo foi relatar as experiências vivenciadas através de práticas letivas aplicadas durante o ensino remoto, atividades desenvolvidas através da Residência Pedagógica de Geografia da Universidade Estadual de Montes Claros. A prática foi desenvolvida com alunos do $6^{\circ}$ ano do ensino fundamental II, na Escola Estadual Carlos Versiani - localizada no município de Montes Claros, no Estado de Minas Gerais (Brasil), na qual incentivamos a participação dos alunos nas aulas, mas, considerando as dificuldades vivenciadas no ensino remoto.

Palavras-chave: Ensino remoto. Ensino de Geografia. Residência Pedagógica.

\begin{abstract}
Given the changes that took place in society, especially in 2020, when humanity was surprised by the Coronavirus pandemic, it was/is essential to develop new educational practices to continue the teaching and learning process. That said, the aim of this article is to report the experiences lived through practices applied in remote learning, activities developed through the Pedagogical Residency (RP) in Geography Unimontes. The practice was developed with students from the 6th year of elementary school II, at the Carlos Versiani State School - located in the municipality of Montes Claros-MG (Brazil), in which we encourage students to participate in classes, but considering the difficulties experienced in remote education.
\end{abstract}


Residência Pedagógica Geografia/UNIMONTES: relato de experiência em tempo de pandemia do COVID-19

Vanessa Tamiris Rodrigues Rocha; Maria Júlia de Souza Leite; Jéssica Lorrany Sant'Ana Rodrigues; Dulce Pereira dos Santos; Rahyan de Carvalho Alves

Keywords: Remote Learning; Teaching of Geography; Pedagogical Residence.

\section{RESUMEN}

Dados los cambios que se produjeron en la sociedad, especialmente en 2020, cuando la humanidad fue sorprendida por la pandemia de Coronavirus, era / es fundamental desarrollar nuevas prácticas educativas para continuar el proceso de enseñanza y aprendizaje. Dicho esto, el objetivo de este artículo es dar a conocer las experiencias vividas a través de prácticas aplicadas en el aprendizaje a distancia, actividades desarrolladas a través de la Residencia Pedagógica (RP) en Geografía Unimontes. La práctica se desarrolló con alumnos de $6^{\circ}$ de primaria II, en la Escuela Estatal Carlos Versiani - situado en el municipio de Montes Claros-MG (Brasil), en la que animamos a los alumnos a participar en las clases, pero considerando las dificultades vividas en la educación a distancia.

Palabras clave: Aprendizaje a distancia; Enseñanza de la Geografía; Residencia Pedagógica.

\section{INTRODUÇÃO}

A Residência Pedagógica (RP) configura-se como um programa que aperfeiçoa a formação prática nos cursos de licenciatura. No Brasil, infelizmente, existem dois grandes desafios na educação, a saber: i) baixa valorização social do magistério e ii) formação inadequada/insuficiente oferecida pelas universidades, que, muitas vezes, ofereceram a mediação do conhecimento aportado com ênfase, na teoria e menos em articulações práticas. Isto posto, no que se refere à qualificação, um dos caminhos para reverter o presente quadro incide acerca da implementação do Programa Residência Pedagógica.

O programa, oferecido pela Coordenação de Aperfeiçoamento Pessoal de Nível Superior (Capes), autarquia vinculada ao Ministério da Educação e Cultura (MEC), está associado à formação das disciplinas da Base Nacional Comum Curricular. O projeto consistia em ser uma forma de integrar a Política Nacional de Formação de Professores para aperfeiçoar à formação prática de alguns graduandos, que cursam algum curso de licenciatura. Desta forma, promove a imersão do graduando na escola de educação básica a partir da segunda metade do seu respectivo curso (GONÇALVES; SILVA; BENTO, 2011). Neste momento, é possível vivenciar a relação teoria e prática, que ocorre sob a supervisão e o acompanhamento de um professor preceptor da rede pública de ensino conveniada.

Conforme Silva (2011), os cursos superiores visam à formação de alunos-cidadãos com competências para intervir junto ao espaço social, em que serão futuros professores. Por isso, se pretende prepará-los para o mercado de trabalho. Ademais, a RP possibilita in loco vivenciar o exercício da docência, ao iniciar a construção da identidade profissional do acadêmico.

Contudo, devido à pandemia do Covid-19, a nova doença causada pelo coronavírus, nomeado Sars-Cov-2, as escolas deixaram de ministrar aulas presenciais para trabalhar no regime não presencial. E, por meio do teletrabalho ou sistema remoto as atividades educacionais 
foram realizadas de maneira virtual para respeitar a necessidade do distanciamento social. Logo, os acadêmicos tiveram que se adequar a esta situação para desempenhar as atividades inerentes a RP de forma virtual, assim, se busca atrelar o conteúdo à realidade do educando.

Desta maneira, o presente trabalho relatar-se-á as experiências vivenciadas e as metodologias desenvolvidas pelas acadêmicas do curso de licenciatura, em Geografia, da Universidade Estadual de Montes Claros (Unimontes); bolsistas do Programa Residência Pedagógica habilitado pela Capes. E, teve como base as observações e práticas realizadas nestes primeiros meses do programa, em que atuavam em duas turmas do $6^{\circ}$ ano do ensino fundamental II, na Escola Estadual Carlos Versiani, localizada no município de Montes Claros, no Estado de Minas Gerais (MG), em Brasil.

Para tanto, utilizou-se como metodologia: $i$ ) revisão bibliográfica sobre as temáticas relacionadas a educação em tempo de pandemia do Covid-19 e ii) apresentação do relato de experiência sobre as metodologias, e materiais utilizados na instituição abordada, ao enfatizar os questionários lúdicos aplicados pelas residentes, como forma de regência.

\section{A PANDEMIA E O ENSINO REMOTO}

No ano de 2020, ocorreu muitas transformações, renovações e instabilidades em diversos âmbitos da sociedade, a saber: políticos, culturais, sociais, econômicos, educacionais, dentre outros. O sistema-mundo depara-se com um enfraquecimento das relações sociais, sendo primordial a necessidade de estabelecer soluções para os problemas decorrentes da pandemia do Covid-19.

Uma das principais preocupações esteve atrelada ao ensino público e privado, no qual as atividades foram temporariamente suspensas e reestruturadas. Isto posto, a Organização para a Cooperação e Desenvolvimento Econômico (OCDE) propôs às instituições educacionais em adaptar os trabalhos através de plataformas e metodologias alternativas, enquanto a saúde humana não estiver segura.

E, no dia 17 de março de 2020, por meio da Portaria número (n.) 343, o Ministério da Educação e Cultura (MEC) manifestou-se sobre a substituição das aulas presenciais por aulas viabilizadas por meios digitais, enquanto durar o cenário pandêmico, para instituição de educação superior integrante do sistema federal de ensino. Posteriormente, esta mesma Portaria recebeu ajustes e acréscimos por meio das Portarias n. 345, de 19 de março de 2020, e n. 356, de 20 de março de 2020. Em 18 de março de 2020, o Conselho Nacional de Educação (CNE) veio a público elucidar aos sistemas e às redes de ensino, de todos os níveis, etapas e 
Residência Pedagógica Geografia/UNIMONTES: relato de experiência em tempo de pandemia do COVID-19

Vanessa Tamiris Rodrigues Rocha; Maria Júlia de Souza Leite; Jéssica Lorrany Sant'Ana Rodrigues; Dulce Pereira dos Santos; Rahyan de Carvalho Alves

modalidades por considerar a necessidade de reorganizar as atividades acadêmicas devido às ações preventivas à propagação da Covid-19 (Portaria 343, BRASIL, 2020; CNE/CP n ${ }^{\circ}$ Covid19).

Ademais, a discussão presente na Constituição da República Federativa do Brasil, de 1998 (BRASIL, 1988), no que tange ao artigo $5^{\circ}$, destacou a necessidade de se preocupar com o direito à vida e esse ser inviolável da pessoa humana. Desse modo, as instituições de ensino veio a adotar o ensino remoto, assim, ampliou o espaço escolar para além dos muros das instituições (CURY, 2020; CORDEIRO, 2020; CARVALHO FILHO, 2020).

As mudanças ocorridas, neste cenário pandêmico, trouxe grandes desafios para a educação, como o entrave ao processo de ensino-aprendizagem decorrentes, sobretudo, pela desigualdade no acesso às técnicas e às ferramentas de tecnologia, como: computadores, celulares e internet de qualidade. Segundo uma pesquisa desenvolvida, em 2019, pela TIC Domicílios, que teve como objetivo mapear o uso das Tecnologias de Informação e Comunicação nos Domicílios Brasileiros, 3 a cada 4 brasileiros usam a internet e desses, 20 milhões de domicílios não a utilizam. Assim, se percebe que o acesso e a utilização de tecnologias não são distribuídos de forma proporcional, no território brasileiro, o que contribui para as disparidades educacionais, em relação ao uso e ao acesso de recursos tecnológicos (BENEDITO; CASTRO FILHO, 2020) (SANTOS, 2004). A saber, uma quantidade significativa de alunos não possuem aparelhos celulares/computadores e acesso à internet, o que influência, diretamente, na participação das atividades propostas pelos docentes.

$\mathrm{Na}$ atualidade, ao discutir algumas situações problemáticas torna-se ainda mais significativo se considerarmos a educação como direito público assegurado pela Constituição Federal (CF), de 1988. Nesta, segundo o artigo número (n.) 205 da CF/88 a “"...] educação, direito de todos e dever do Estado e da família, será promovida e incentivada com a colaboração da sociedade, visando ao pleno desenvolvimento da pessoa, seu preparo para o exercício da cidadania e sua qualificação para o trabalho" (BRASIL, 1988, p. 123). Assim, a educação passa a ser uma garantia aos jovens para o seu pleno desenvolvimento, ao ter em vista a "[...] igualdade de condições para o acesso e permanência na escola” (BRASIL, 1988, p.123).

Desse modo, acredita-se que a educação tem o poder de ampliar as potencialidades dos alunos e seus aprendizados, assim como, auxiliar crianças e jovens no processo de interação e desenvolvimento social, afetivo e na construção da própria humanização. Pois, educar instrui o aluno acerca de alguns conhecimentos, em especial, o científico, porque esse se apreende, de modo geral nas instituições de ensino pública ou privado. Assim, as instituições de ensino proporcionam entendimento dos conteúdos curriculares e dos modos de vida, da inserção do 
aluno na sociedade, enquanto ser social, porque, de fato, se torna um cidadão crítico e reflexivo. Educar é, portanto, fazer com que o aluno floresça e receba a educação que lhe permita conjecturar sobre o seu modo de vida à luz das alternativas. Atributos que foram desfalcados no ensino remoto, sobretudo pela falta de preparação dos envolvidos para lidar com o modelo de ensino online (BRIGHOUSE, 2016; YOUNG, 2011).

Convém ressaltar ainda, a questão das instituições de ensino, professores, estudantes e família não estarem preparados, a priori, para tamanha mudança. O professor teve que readaptar e reinventar suas práticas de ensino, seu ambiente e sua rotina de trabalho para demonstrar um aspecto de insegurança na atuação desse sistema remoto, como apresentado por uma pesquisa realizada pelo Instituto Península, na qual se opta por implementar um cronograma de pesquisas para avaliar o sentimento e a percepção dos educadores brasileiros em cada um dos estágios do Covid-19. Realiza-se uma pesquisa quantitativa através de questionário online, disparados via e-mails convite para bases diversas, respondidos através da plataforma Survey Monkey. Foram coletadas 2.400 respostas de professores da educação básica de todo o Brasil, da educação infantil ao ensino médio e com isso contemplou diferentes modalidades e níveis de ensino (INSTITUTO PENÍNSULA, 2020).

Os alunos e seus familiares sentiram um impacto, em relação ao novo sistema adotado. Uma vez que, muitos tiveram que adaptar suas rotinas de estudos, atreladas a ajuda de algum familiar ou sozinhos, porque a presença do professor só se fez de forma virtual. Ainda, segundo o Instituto Península, 60\% dos professores acreditam que os alunos não evoluíram na aprendizagem, em 2020. Isto ocorreu, tanto pela dificuldade dos alunos em ter um espaço de concentração em casa quanto pela falta de recursos e preparo dos estudantes, haja vista que, foram inseridos no ensino digital de maneira abrupta e inesperada. Por conseguinte, ocasionou agravamento na desigualdade educacional entre os alunos mais desfavorecidos.

A partir deste momento surgiu outro dilema: o cumprimento dos conteúdos curriculares preestabelecidos. Passando a existir, assim, uma preocupação muito maior em vencer os conteúdos do que a forma como seriam ensinados e se haveria aprendizagem. Limitar a educação, da forma citada, foi estabelecer as semelhanças educacionais como relações puramente econômicas, ao representar o estudante como consumidor e o processo educativo como mercadoria (BIESTA, 2013).

O ensino da geografia, especificamente, merece grande notoriedade no cenário atual, porque auxilia no estudo do homem e suas relações com a sociedade. De acordo com Freire (2014), a educação, a escola e o ensino de geografia contribui grandemente para resistir, enfrentar e promover igualdade, justiça e aprendizagem. Ademais, o autor citado anteriormente 
Residência Pedagógica Geografia/UNIMONTES: relato de experiência em tempo de pandemia do COVID-19

Vanessa Tamiris Rodrigues Rocha; Maria Júlia de Souza Leite; Jéssica Lorrany Sant'Ana Rodrigues; Dulce Pereira dos Santos; Rahyan de Carvalho Alves

dialoga com a necessidade de trabalhar criticamente a importância das relações entre o indivíduo e a realidade do mundo que o cerca. Assim, entendemos a urgência de buscarmos um resgate desse princípio freudiano, especialmente, em tempos de pandemia (FREIRE, 2014).

Diante do exposto, percebemos o quão necessário foi buscar alternativas não só para amenizar o distanciamento educacional no processo de ensino-aprendizagem, mas para atenuar as disparidades educacionais e sociais. A saber, a Residência Pedagógica - Geografia teve uma participação efetiva neste processo ao dar suporte aos professores e alunos do ensino básico e transmitir mais ânimo e coragem para se superar as dificuldades.

\section{RELATO DE EXPERIÊNCIA E APLICAÇÃO DE QUESTIONÁRIOS LÚDICOS}

A forma como um professor trabalha e desenvolve os conteúdos que devem ser tratados em sala de aula, seja esta presencial ou virtual, influência diretamente no grau de compreensão e assimilação dos discentes, por isso, há criação de metodologias mais acessíveis a realidade de cada residente por ser esse um dos principais objetivos da RP.

Nesta busca por recursos que favoreçam o processo de ensino e aprendizagem, obtevese o desenvolvimento das metodologias ativas. Segundo Borges e Alencar (2014, p. 120) as metodologias ativas “[...] são formas de desenvolver o processo do aprender que os professores utilizam na busca de conduzir a formação crítica dos futuros cidadãos, nos mais diversos níveis de ensino".

As metodologias ativas foram consideradas alternativas para o docente alcançar maior envolvimento dos alunos ao contornar situação problemática do desinteresse dos estudantes, o qual muitas vezes estava relacionado à existência de aulas baseadas em perspectivas tradicionais de ensino. Para Moreira e Ribeiro (2016), as metodologias ativas são importantes para a formação crítica e reflexiva, assim como, para proporcionar um ensino construtivista para favorecer a autonomia, e a curiosidade aos educandos.

Ao corroborar com esta perspectiva, Rupel (2011, p. 2) denotou que: “[...] muitas vezes durante o desenvolvimento dos conteúdos de Geografia no cotidiano da sala de aula, as atividades tornam-se cansativas e pouco atrativas para os alunos, principalmente porque nem sempre se buscam metodologias alternativas para motivá-los". O uso de atividades lúdicas estimulam a participação ativa dos alunos, simultaneamente, incita o discente querer aprender. Neste viés, torna-se necessário o docente aprimorar as metodologias de ensino e diversificar o uso de recursos didáticos para aplicar o processo de ensino e aprendizado positivamente.

Contudo, é evidente o grande desafio relacionado à implantação de metodologias ativas, melhoria na comunicação e aprendizagem efetiva. Acredita-se que é possível afirmar que as 
Residência Pedagógica Geografia/UNIMONTES: relato de experiência em tempo de pandemia do COVID-19

Vanessa Tamiris Rodrigues Rocha; Maria Júlia de Souza Leite; Jéssica Lorrany Sant'Ana Rodrigues; Dulce Pereira dos Santos; Rahyan de Carvalho Alves

aulas online torna-se produtivas e prazerosas ao professores contemporâneos, porque visam motivar os alunos em continuar seus estudos e não desanimar perante aos problemas, desafios encontrados para estudar em ambiente não escolar.

Segundo Pasini et al. (2020), a pandemia trouxe uma revolução pedagógica para o ensino presencial, a ser considerada a mais forte desde o surgimento da tecnologia contemporânea de informação e comunicação. Com instituições de ensino fechadas em todo o Brasil, a tecnologia é uma importante aliada da educação. Já que, é necessário utilizar meios digitais, como aplicativos de mensagens, canais de televisão (TV) aberta, dentre outros.

Diante desse novo cenário e modos de vida reeducados, ao considerar o atual estilo social, a RP foi reajustada para atender às necessidades relacionadas à prevenção contra o vírus para evitar o contato físico. Ao desenvolvermos a prática pedagógica, na escola em questão, percebemos que a mesma utilizava como principal ferramenta de comunicação e para auxílio no processo de ensino/aprendizagem um grupo no aplicativo WhatsApp (wpp), assim, cada turma tem um grupo, onde estão presentes os professores de todas as disciplinas, incluindo os residentes. Podemos destacar, assim, a importância do uso deste aplicativo, tanto para a comunicação, quanto para o compartilhamento de conteúdo.

Através do aplicativo foram destinados dias e horários para a disciplina de Geografia, a professora regente disponibilizou o conteúdo e as atividades do Plano de Estudo Tutorado (PET), o qual foi organizado pela Secretaria de Estado de Educação de Minas Gerais. Como forma de organizar o grupo, uma vez que, todos os professores da turma faziam uso dele. Desse modo, havia um cronograma de postagens, no qual a disciplina de Geografia integrava a terçafeira. No entanto, a assistência individual ou até mesmo em grupo ocorria durante o decorrer da semana, porque os alunos tinham a disponibilidade de sanar as possíveis dúvidas com o docente, sobre o conteúdo trabalhado. E, tanto o preceptor quanto os alunos contavam com o apoio das residentes em todas as aulas.

Realizamos a RP nesta escola através de monitorias todas as terças-feiras, acompanhando também as aulas de geografia do Programa Se Liga na Educação - programa televisivo transmitido na Rede Minas, de segunda-feira a sexta-feira, pela manhã. Ressalta-se que, todos os cronogramas eram-no repassados com antecedência pela preceptora. Contudo, não bastava ter apenas esse canal como ferramenta didática. E, como forma de dinamizar o aprendizado, foram pensados e estruturados, para algumas aulas, questionários lúdicos criados no Google Forms - serviço gratuito para criar formulários online lançado pela empresa Google - que oferecia uma série de serviços e produtos baseados na internet. Está com apenas 20 anos de existência e já é considerada a ferramenta de busca mais utilizada em nível mundial 
(MOTA, 2019). O mesmo pode proporcionar o desenvolvimento de atividades mais criativas e produtivas. Para tanto, o professor acessava o site, por meio do endereço, a saber: https://www.google.com/pt-BR/forms/about/.

O primeiro formulário assemelha-se a um quiz geográfico, porque abordavam temáticas relacionadas às semanas um, dois, três e quatro, ciclo hidrológico; bacias hidrográficas; poluição hídrica; clima e tempo atmosférico, dentre outros. O PET volume sete foi resolvido pelos alunos do $6^{\circ}$ ano do ensino fundamental II, em dezembro de 2020, via WhatsApp. Contendo questões de múltipla escolha, verdadeiro ou falso e utilizando imagens/charges (FIGURA 1).

Figura 1 - Formulário aplicado para os alunos do $6^{\circ}$ ano do Ensino Fundamental II.

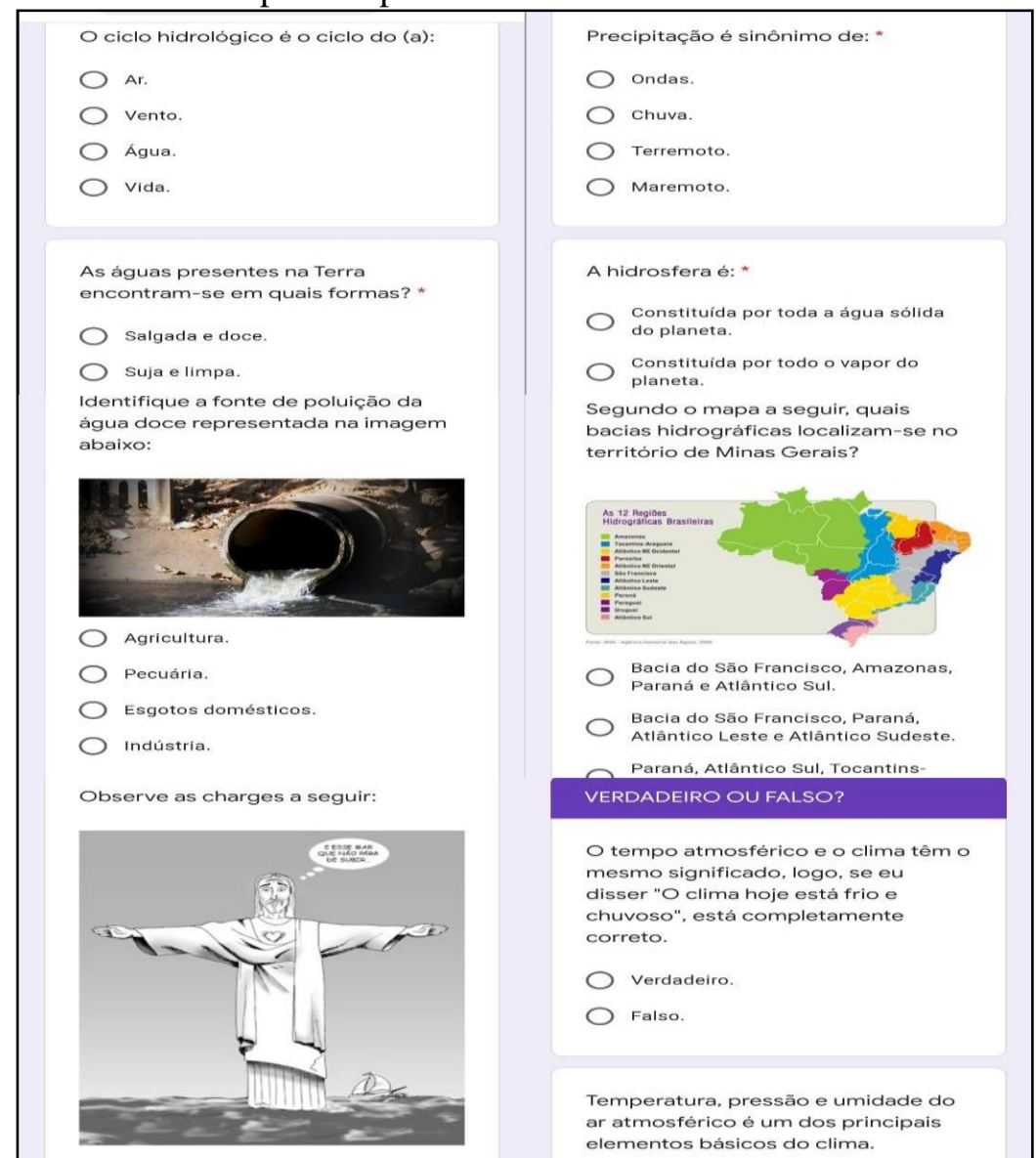

Fonte: https://www.google.com/intl/pt-BR/forms/about/. Acessado em: 01 set. 2021

Organização: Autores, 2021.

O segundo formulário baseia-se na temática "Os tipos de cidades”, presente na terceira semana do PET volume um, aplicado em março de 2021, por meio do grupo de wpp. Nesse foram desenvolvidas em um primeiro momento, algumas perguntas relacionadas aos tipos de cidades existentes (planejadas, espontâneas, portuárias). Em seguida, o mesmo propunha um 
Residência Pedagógica Geografia/UNIMONTES: relato de experiência em tempo de pandemia do COVID-19 Vanessa Tamiris Rodrigues Rocha; Maria Júlia de Souza Leite; Jéssica Lorrany Sant'Ana Rodrigues; Dulce Pereira dos Santos; Rahyan de Carvalho Alves

desafio aos discentes, os quais deveriam descobrir qual era a cidade evidenciada na imagem utilizando-a como fonte de análise (FIGURA 2).

Figura 2 - Formulário aplicado para os alunos do $6^{\circ}$ ano do Ensino Fundamental II.

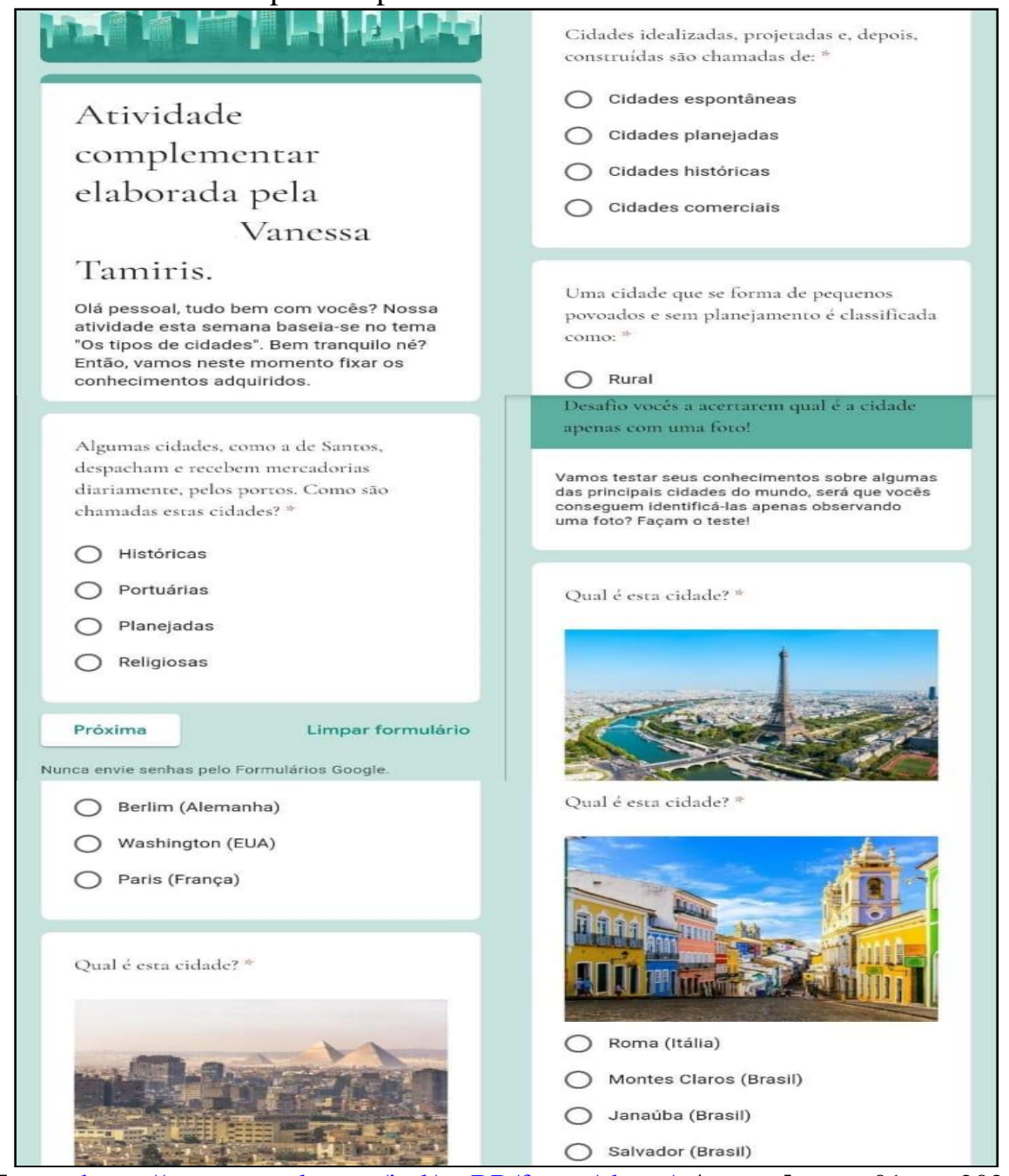

Fonte: https://www.google.com/intl/pt-BR/forms/about/. Acessado em: 01 set. 2021

Organização: Autores, 2021.

O terceiro formulário, assemelha-se ao Jogo “Qual é a música?”. Sua dinâmica era para os alunos escrever uma música e em sua composição deveria ter exemplos de meios de transporte rodoviário, ferroviário, aeroviário e aquaviário, temática abordada no PET volume um, semana quatro (FIGURA 3). Este foi disponibilizado aos discentes pelo grupo do WhatsApp, em abril de 2021.

Figura 3 - Formulário aplicado para os alunos do $6^{\circ}$ ano do Ensino Fundamental II. 
Residência Pedagógica Geografia/UNIMONTES: relato de experiência em tempo de pandemia do COVID-19 Vanessa Tamiris Rodrigues Rocha; Maria Júlia de Souza Leite; Jéssica Lorrany Sant'Ana Rodrigues; Dulce Pereira dos Santos; Rahyan de Carvalho Alves

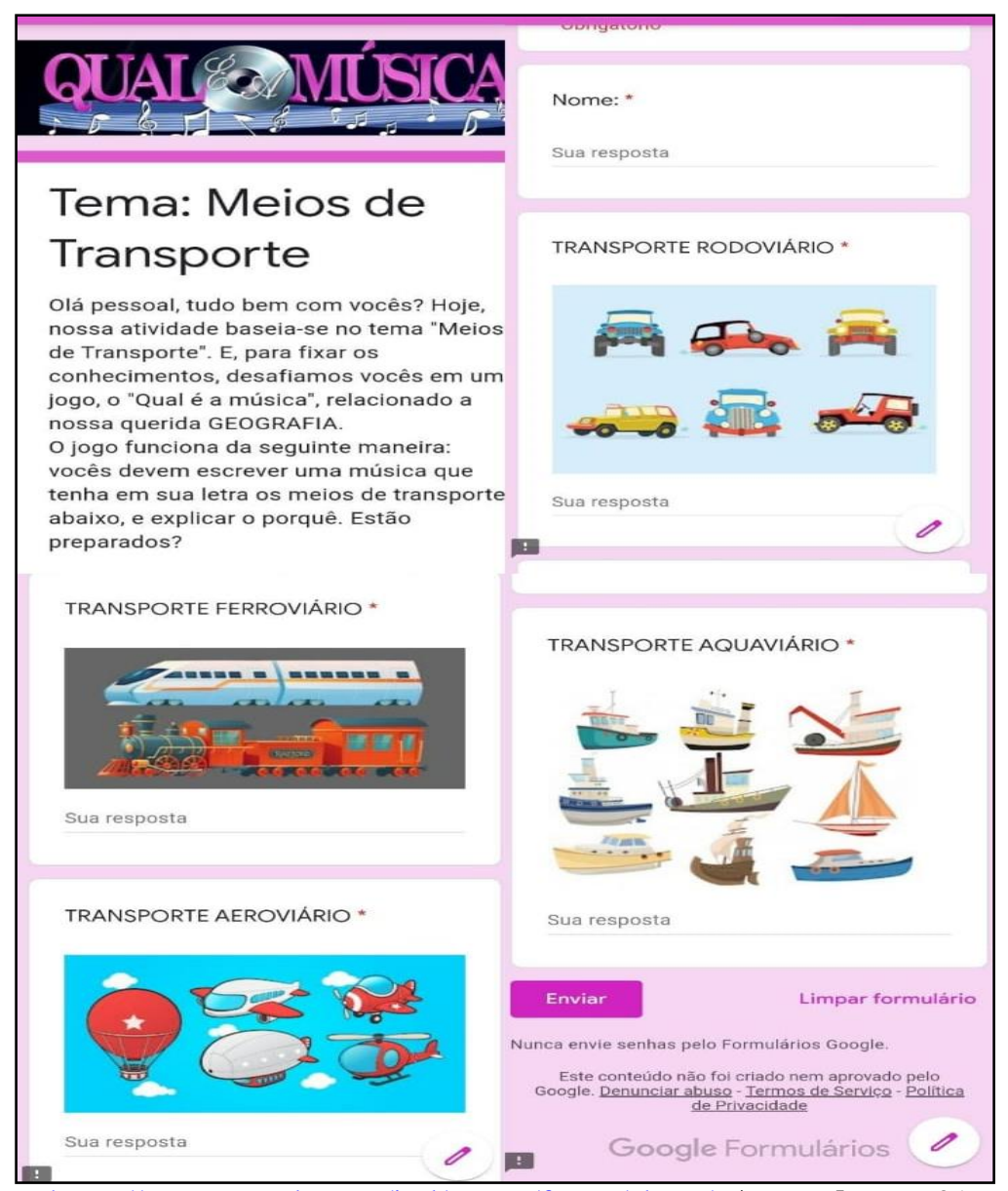

Fonte: https://www.google.com/intl/pt-BR/forms/about/. Acessado em: 01 set. 2021 Organização: Autores, 2021.

O quarto formulário aplicado visou fixar o conteúdo abordado no decorrer da primeira semana do PET volume dois, o qual consistia na diferenciação entre paisagens naturais e paisagens culturais (FIGURA 4). O mesmo foi trabalhado com a turma por meio do grupo de wpp, em maio de 2021.

Figura 4 - Formulário aplicado para os alunos do $6^{\circ}$ ano do Ensino Fundamental II. 


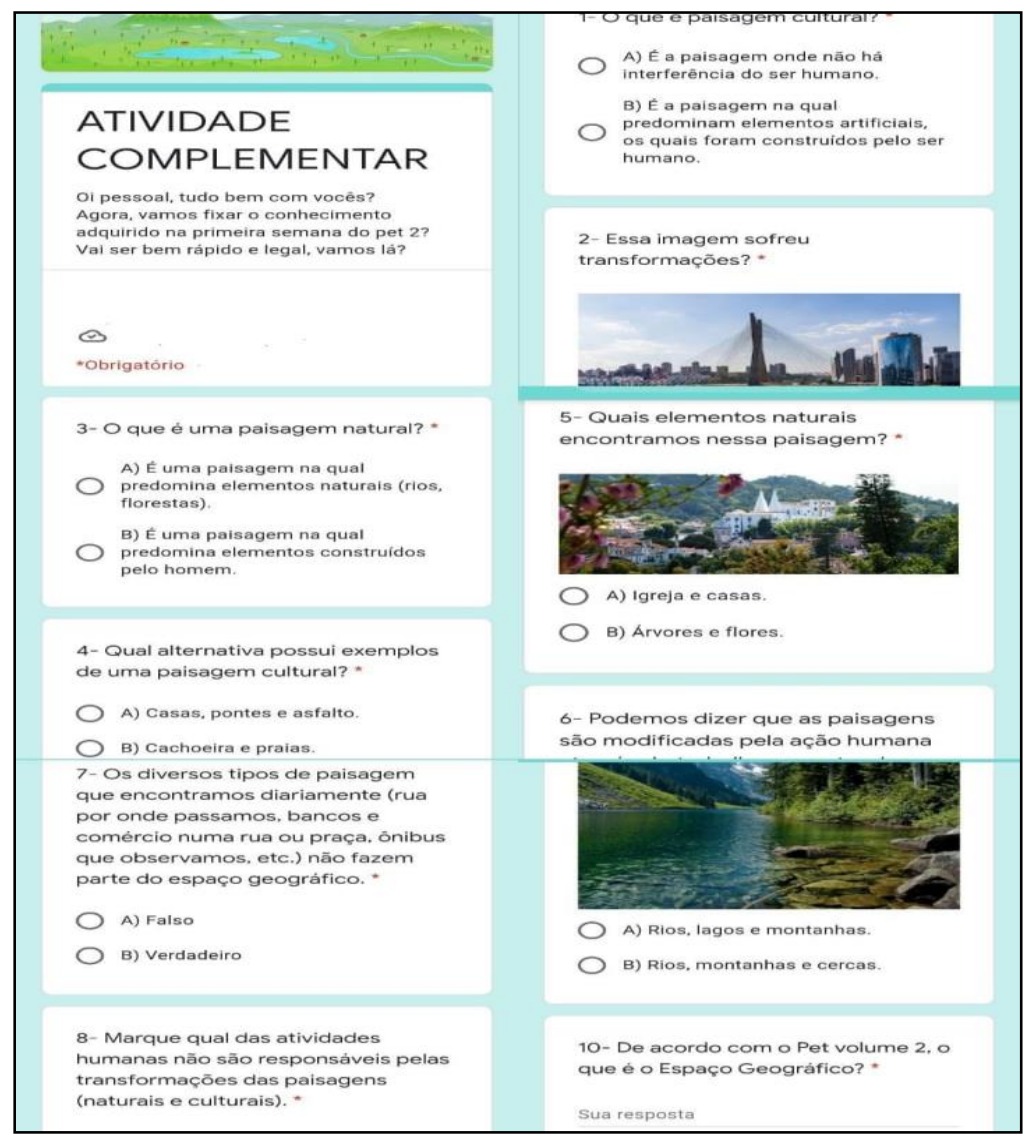

Fonte: https://www.google.com/intl/pt-BR/forms/about/. Acessado em: 01 set. 2021

Organização: Autores, 2021.

Após a aplicação dos questionários, nós nos colocávamos à disposição dos alunos para sanar as dúvidas advindas dos mesmos, ou a curiosidade sobre o número de acertos. Alguns alunos nos mandavam mensagens pelo wpp questionando quais foram os motivos dos erros, e, assim, íamos sanando as dúvidas de cada um.

Esta metodologia proporcionou grandes benefícios, tanto para o professor quanto para o aluno, uma vez que, tornou o processo de ensino e aprendizagem prático, dinâmico e prazeroso. Relacionado ao docente, vale ressaltar, a praticidade para avaliar os alunos acerca da assimilação dos conteúdos abordados, uma vez que, as respostas eram visualizadas facilmente por meio de planilha gerada no próprio site, com rapidez e praticidade. Ademais, o uso de formulários despertava o interesse dos discentes, os quais se sentiam instigados, desafiados, despertados. Nessas aulas notamos uma maior participação dos discentes em relação aos dias anteriores, quando seguíamos com o cronograma normal. Assim, percebemos que os alunos gostavam de serem instigados, estimulados a participarem das aulas. 
Residência Pedagógica Geografia/UNIMONTES: relato de experiência em tempo de pandemia do COVID-19

Vanessa Tamiris Rodrigues Rocha; Maria Júlia de Souza Leite; Jéssica Lorrany Sant'Ana Rodrigues; Dulce Pereira dos Santos; Rahyan de Carvalho Alves

\section{CONSIDERAÇÕES FINAIS}

Ao ter em vista que alguns alunos tinham acesso limitado à internet e tem falta de recursos suficientes para o desenvolvimento de seu conhecimento fez-se necessário, o retorno das atividades. Contudo, podemos perceber que, na maioria dos casos, o baixo retorno dos alunos não estava diretamente ligado ao desinteresse, mas, sim, devido às dificuldades enfrentadas em seu cotidiano.

A partir disso, se percebe a necessidade de efetivação de atividades que consigam um alcance maior dos discentes. As metodologias ativas, como aborda Freire (2014), principalmente, no ensino remoto, se faz extremamente necessária, como forma de prender a atenção do aluno, ao fazer, assim, com que ele interaja mais com a disciplina.

Através das implementações de metodologias ativas, foi possível observar as contribuições para o processo de ensino/aprendizagem. Ao invés dos discentes terem a falsa sensação de terem aprendido determinado conteúdo, porque lhes foi apresentado de forma expositiva, os alunos experimentam situações de aprendizagem que foram mais significativas à sua realidade.

Dessa forma, o ensino remoto torna-se menos cansativo e atinge um alcance maior de seu público-alvo. Assim, foi possível acreditar em uma geração de alunos que sentirão prazer na busca pelo conhecimento, através de uma noção clara de que seu aprendizado não termina na sala de aula.

A participação da Residência Pedagógica foi primordial para o suporte aos professores e alunos. Os acadêmicos participando das aulas movimentavam os grupos e faziam com que os alunos que haviam perdido o ânimo de acessar o grupo de WhatsApp voltaram a checar as mensagens. Além de estarem disponíveis para os professores, auxiliando nas intervenções e pensando metodologias, tendo em vista, que muitos destes estavam se sentindo esgotados e cansados ao longo deste cenário pandêmico.

Desta forma, desenvolvemos metodologias de nosso alcance, buscamos romper, de fato, os muros das salas de aula, agora de forma online, mas mantendo o ato de consumir ideias, criálas e recriá-las para buscar uma educação de qualidade e promissora (FREIRE, 1981).

\section{REFERÊNCIAS}

BENEDITO, Samiles Vasconcelos Cruz; DE CASTRO fre, Pedro Júlio. A educação básica cearense em época de pandemia de Coronavírus (COVID-19): perspectivas e desafios no cenário educacional brasileiro. In: Revista Nova Paideia-Revista Interdisciplinar em Educação e Pesquisa, v.2, n.3, p. 58-71, 2020. 
Residência Pedagógica Geografia/UNIMONTES: relato de experiência em tempo de pandemia do COVID-19 Vanessa Tamiris Rodrigues Rocha; Maria Júlia de Souza Leite; Jéssica Lorrany Sant'Ana Rodrigues; Dulce Pereira dos Santos; Rahyan de Carvalho Alves

BIESTA, Gert. The beautiful risk of education. United States: Paradigman Publishers, 2013.

BORGES, Tiago Silva.; ALENCAR, Gidélia. Metodologias ativas na promoção da formação crítica do estudante do ensino superior. In: Cairu em Revista; $n^{\circ}$ 04, p. 119-143, julho/agosto 2014.

BRASIL. Constituição da República Federativa do Brasil. Brasília, DF: Senado Federal, 1988.

BRIGHOUSE, Harry. Sobre educação. São Paulo: Editora Unesp, 2016.

CARVALHO FILHO, Odair Ribeiro de; GENGNAGEL, Claudionei Lucimar. Ensino de geografia em tempos da covid-19: tecnologias e uso de plataformas de educação para o ensino remoto em Ribeirão Preto/SP e em Passo Fundo/RS. In: Revista Ensaios de Geografia, Niterói, vol. 5, nº 10, p. 88-94, julho de 2020.

CORDEIRO, Karolina Maria de Araújo. O Impacto da Pandemia na Educação: A Utilização da Tecnologia como Ferramenta de Ensino, 2020.

CURY, Carlos Roberto Jamil. Educação escolar e pandemia. Pedagogia em Ação, v. 13, n. 1, p. 8$16,2020$.

DOMICÍlIOS, T. I. C. Pesquisas e Indicadores-2019. Domicílios com acesso à internet, 2019. Disponível em: https://www.ibge.gov.br/estatisticas/sociais/populacao/17270-pnadcontinua. html?edicao=23205\&t=destaques. Acesso em: 22 fev. 2021.

FREIRE, Paulo. Pedagogia da Autonomia. 15. ed. Rio de Janeiro: Paz e Terra, 2014.

FREIRE, Paulo. Pedagogia da autonomia: saberes necessários à prática educativa. São Paulo: Paz e Terra, 1981.

GONÇALVES, Sheila Maria Santos; SILVA, João Felix da; BENTO, Maria das Graças. Relato sobre o Programa de Residência Pedagógica: Um olhar sobre a Formação Docente. In: Rev.Mult. Psic., Dezembro/2019, vol.13, n.48, p. 670-683.

INSTITUTO PENÍNSULA. Sentimento e percepção dos professores brasileiros nos diferentes estágios do Coronavírus no Brasil. Disponível em: https://www.institutopeninsula.org. br/pesquisa-sentimento-e-percepcao-dosprofessores-nos-diferentes-estagios-do-coronavirus-nobrasil/. Acesso em: 20 fev. 2021.

INSTITUTO PENÍNSULA. Pesquisa do Instituto Península aponta: 60\% dos professores acreditam que os alunos não evoluíram no aprendizado em 2020. Disponível em: institutopeninsula.org.br/pesquisa-do-instituto-peninsula-aponta-60-dos-professoresacreditam-que -os-alunos-nao-evoluiram-no-aprendizado-em2020/. Acesso em: 20 fev. 2021.

MOREIRA, Jonathan Rosa; RIBEIRO, Jefferson Bruno Pereira. Prática pedagógica baseada em Metodologia Ativa: Aprendizagem sob a perspectiva do letramento informacional para o ensino na educação profissional. In: Outras Palavras, v.12, n. 2, Brasília, 2016. Disponível em: http://revista.f aculdadeprojecao.edu.br/article/view/722. Acesso em: 08 set. 2021. 
MOTA, Janine da Silva. Utilização do Google Forms na pesquisa acadêmica. Disponível em: https://revista.unitins.br/index.php/humanidadeseinovacao/article/view/1106. Acesso em: 01 set. 2021.

RUPEL, Marcia Aparecida Pavelski. Atividades lúdicas: proposições metodológicas para o ensino de geografia escolar. Dia a dia da educação, Curitiba, 2011. Disponível em: http://www.diaadiaeducacao.pr.gov.br. Acesso em: 01 set. 2021.

PASINI, Carlos Giovani Delevati; CARVALHO, Élvio de; ALMEIDA, Lucy Hellen Coutinho. A educação híbrida em tempos de pandemia: algumas considerações. Disponível em: https://www.ufsm.br/app/uploads/sites/820/2020/06/Textos-para-Discussao-09-Educacao-Hibrida -em-Tempos-de-Pandemia. Acesso em: 25 de jan. 2021.

SANTOS, Milton. A Natureza do Espaço - Técnica, Tempo, Razão e Emoção. $4^{\mathrm{a}}$ ed. São Paulo: Edusp, 2004.

SILVA, Jorge Luiz Barcellos da. Quais saberes constituem um bom professor de Geografia? In: TONINI, Ivaine Maria et al (Orgs.). O ensino de Geografia e suas composições curriculares. Porto Alegre, RS: UFRGS, 2011. p. 221-231.

YOUNG, Michael. O futuro da educação em uma sociedade do conhecimento: o argumento radical em defesa de um currículo centrado em disciplinas. In: Revista Brasileira de Educação, v. 16, n. 48, p. 609-633, 2011.

Artigo recebido em: 30 de setembro de 2021.

Artigo aceito em: 18 de novembro de 2021.

Artigo publicado em: 21 de fevereiro de 2022. 